\title{
EDUCAÇÃO PROFISSIONAL E O CURSO SUPERIOR DE UM CAMPUS DO IF GOIÁS: PERCEPÇÃO DOS ALUNOS NO CONTEXTO DO ESTÁGIO SUPERVISIONADO
}

\author{
Gilmara Barbosa de Jesus \\ Yara Fonseca de Oliveira e Silva \\ Universidade Estadual de Goiás (UEG), Aparecida de Goiânia, Goiás, Brasil
}

\begin{abstract}
Resumo: Este estudo busca desvelar a percepção dos alunos de um campus do Instituto Federal de Educação, Ciências e Tecnologia de Goiás (IFG) sobre sua formação e inserção no mundo do trabalho. A questão de interesse é: qual a percepção desses alunos sobre sua formação inicial, assertivas e fragilidades para acessar o mundo do trabalho, para o exercício da docência e, ainda, sua percepção sobre a articulação e integração da teoria e prática durante seu curso? O referencial teórico adotado destaca, dentre outros, Nóvoa (1995), Pimenta (1995), Tardif (2010) e Candau (2013). Esta pesquisa se caracteriza como um trabalho de natureza qualitativa com uso de roteiro de entrevista para alunos do curso de Licenciatura em Química. Ao interpretar e analisar a percepção dos alunos do curso constatou-se uma insatisfação dos entrevistados em relação à articulação entre teoria e prática no que tange o estágio supervisionado. Em contrapartida, é possível perceber que o IFG tem se preocupado com as mudanças significativas que interferem na proposta curricular de seu curso, por apresentar uma redefinição de seu currículo e avanço da matriz curricular em relação às práticas de ensino e didática.
\end{abstract}

Palavras-chave: Educação Profissional. Estágio supervisionado e didática. Formação integral e currículo. Teoria e prática.

\section{INTRODUÇÃO}

Este estudo ${ }^{1}$ busca desvelar a percepção de alunos que se encontram no estágio supervisionado, sendo este ofertado no último período do curso superior de Licenciatura em Química, do Instituto Federal de Educação, Ciências e Tecnologia de Goiás (IFG), Campus Uruaçu, norte de Goiás, sobre sua formação, inserção e atuação no mundo do trabalho.

Na perspectiva de formar profissionais para atuação na Educação Básica e Superior, o IFG tem como objetivo a formação de professores nas áreas de ciências e matemática, principalmente, para o cumprimento do artigo $8^{\circ}$ da Lei n. 11.892/2008, que estabelece a oferta de no mínimo $20 \%$ do total de vagas a cada ano letivo para atender a formação de professores (BRASIL, 2008). Na mesma legislação, tem-se a prerrogativa de 
que, referindo-se ao estágio supervisionado, no âmbito dos cursos de licenciaturas do IFG, haverá a integração com a realidade das instituições de ensino e seus ambientes educativos desde o início do curso, ou seja, desde o ingresso do aluno na formação superior.

O Ministério da Educação e Cultura (BRASIL, 2008) sugere que o currículo dos cursos de licenciaturas nos Institutos Federais de Educação, Ciência e Tecnologia deverão ter três núcleos de ensino, a saber: 1. núcleo comum (composto pelo Núcleo Básico e pelo Núcleo Pedagógico); 2. núcleo específico para a formação profissional na área do curso; e o 3. núcleo complementar. No que se refere ao estágio curricular supervisionado, a orientação é de que as atividades da prática pedagógica devem ser desenvolvidas não apenas na prática profissional, mas em todos os núcleos, ou seja, perpassando por todo o curso (BRASIL, 2008).

Sendo assim, questiona-se aos alunos, que se encontram no estágio supervisionado, no último ano do curso de Licenciatura em Química: qual sua percepção sobre sua formação inicial, assertivas e fragilidades para acessar o mundo do trabalho, para o exercício da docência e, por fim, sobre a articulação e integração da teoria e prática durante seu curso?

A partir da investigação com os alunos do curso citado anteriormente, suas respostas foram contextualizadas levando-se em consideração a proposta curricular do curso de Licenciatura em Química do IFG (2008; 2018), junto às contribuições sobre didática e estágio supervisionado por Candau (2013) e Pimenta (1995), os conceitos de saberes docentes defendidos por Pimenta (2012; 2002), Tardif (2010), Pimenta e Anastasiou (2010). Considerou-se também os conceitos de identidade docente e perfil do professor de Educação Profissional defendidos pelos autores Pimenta (2012); Nóvoa (1995) e Tardif e Raymond (2000).

Dado isso, esta pesquisa se caracteriza como um trabalho de natureza qualitativa, com base na descrição e interpretação dos dados coletados a partir de entrevista com roteiro contendo quatro questões norteadoras sobre currículo, formação para o mundo do trabalho e estágio curricular supervisionado. $O$ grupo de alunos participantes foram cinco (40\%) de um total de 12 (doze) que possuem coeficiente de progressão acima de 80\% para integralizar o curso de Licenciatura em Química (iniciaram em meados de 2014 e finalizaram em 2018).

Este estudo está dividido em três seções, além dessa introdução e das considerações finais. A primeira seção trata da educação profissional e de suas diretrizes curriculares, bem como mostra o papel do IFG e sua proposta de formação integral, omnilateral (de todos os lados; com objetivos mais gerais, para objetivos de toda vida) e a sua proximidade com o mundo do trabalho, considerando que a educação profissional tem em sua diretriz curricular a integralidade do ensino e uma formação omnilateral, em que se articulam conhecimentos gerais e específicos. E a segunda trata de discutir sobre os saberes docentes que estruturam essa profissão e estão intrinsecamente associados à construção da identidade dos professores. E a terceira seção apresenta os resultados e a análise deste estudo.

\section{EDUCAÇÃO PROFISSIONAL: CURRÍCULO, DIDÁTICA E ESTÁGIO}


JESUS, G. B. de; SILVA, Y. F. de Oe

A Educação Profissional no Brasil tem tido, no decorrer de sua trajetória, mudanças de concepção, legislações com repercussões no currículo e na relação teoria e prática, pois tem se proposto a romper paradigmas e clarificado seus processos formativos ao menos em sua proposta teórica ou política institucional (IFG, 2013). Busca ainda deixar de lado a figura assistencialista, configurando-se como ferramenta estratégica para diversos âmbitos como o político, econômico, jurídico e cultural, e, por fim, tornando-se uma modalidade de importância para sociedade.

Atualmente, as Diretrizes Curriculares Nacionais para a Educação Profissional consideram a educação como um "Direito inalienável do cidadão, em termos de direito do trabalhador ao conhecimento" (BRASIL, 2011, p. 5). A luta atual é a de que não deixemos essa educação se transformar nas mãos do Estado, como uma ferramenta para adequar paradigmas e reformas às demandas do mercado. Portanto, as diretrizes e os princípios que norteiam a Educação Profissional no Brasil propõem uma crescente ampliação de sua função social, a participação democrática efetiva de seus segmentos internos e a conquista da autonomia institucional (IFG, 2013). O objetivo central da Educação Profissional não é formar profissionais para o mercado, mas sim cidadãos para o mundo do trabalho, "o qual poderia ser tanto técnico, como um filósofo, um escritor ou tudo isto. Significa superar o preconceito de classe de que um trabalhador não pode ser um intelectual, um artista". (PACHECO, 2010, p. 10-11).

Ele ainda argumenta que:

Os Institutos Federais de Educação Ciência e Tecnologia são a síntese daquilo que de melhor a Rede Federal construiu ao longo de sua história e das políticas de educação profissional e tecnológica do governo federal. São caracterizados pela ousadia e inovação, necessárias a uma política e um conceito que buscam antecipar aqui e agora as bases de uma escola contemporânea do futuro e comprometida com uma sociedade radicalmente democrática e socialmente justa. (PACHECO, 2010, p. 11).

Nesse sentido, a concepção de Educação Profissional e Tecnológica dos Institutos Federais é orientada pelas ações de ensino, pesquisa e extensão e baseia-se na integração "entre ciência, tecnologia e cultura como dimensões indissociáveis da vida humana e, ao mesmo tempo, no desenvolvimento da capacidade de investigação científica, essencial à construção da autonomia intelectual" (PACHECO, 2010, p. 15), ou seja, uma formação contextualizada que potencializam a ação humana.

Disso, tem-se uma educação profissional objetivada pela busca constante da qualidade social da educação e para a construção de uma sociedade solidária, inclusiva e justa. Percebe-se anseio e preocupação voltados para as demandas nos diversos contextos, configurando prioritariamente uma educação para formação omnilateral/integral e humana do indivíduo, integrando-o em seu meio social e cultural, econômico e político.

Segundo Ciavatta (2015), por sua vez, a formação humana busca garantir o direito a:

Uma formação completa para a leitura do mundo e para a atuação como cidadão pertencente a um país, integrado dignamente à sua sociedade política. 
Formação que, neste sentido, supõe a compreensão das relações sociais subjacentes a todos os fenômenos. (CIAVATTA, 2015, p. 85).

A partir dessas contribuições e reflexões críticas, a educação profissional pode ser visualizada com uma estreita ligação com o mundo do trabalho. Estreita não no sentido de pequena, mais sim de próxima e em constante dinâmica para formação de seus sujeitos. Nos documentos que defendem essa modalidade há o anseio de romper com a lógica dualista de educação e proporcionar uma formação que vislumbre o mundo do trabalho e a omnilateralidade do homem. Ainda que os educadores que atuam na Educação Profissional assumam uma postura que supere o modelo disciplinar e que se apropriem de práticas pedagógicas do conhecimento de forma integrada, desenvolvendo um trabalho que seja reflexivo e criativo, poderão assim também promover as contextualizações didáticas que permitirão uma construção de autonomia dos alunos, fator primordial para sua ação e atuação frente aos paradigmas do mundo do trabalho (PACHECO, 2010).

Manfredi (2002) afirma que a educação no e para o trabalho admite reflexos dos fatores socioculturais, pois é um processo complexo de socialização e aculturação de jovens e adultos nos espaços de trabalho, entrecruzando-se com as aprendizagens realizadas em outros espaços socioculturais: bairro, escola, família, sindicato, partido, movimentos sociais e políticos, além de diferentes momentos da vida de cada sujeitotrabalhador.

No contexto de dualidade de formação, em que era presente uma educação "diferente" para os trabalhadores, educação unilateral (apenas de um só lado; com objetivos específicos), principalmente àqueles de classe popular, surge a necessidade de uma integração na formação do homem em que sejam os "processos de aprendizagem multifacetados, mediados por relações de historicidade entre sujeitos, contextos e tempos" (MANFREDI, 2002, p. 54). Necessita-se formar o indivíduo omnilateralmente. A exigência da onilateralidade (omnilateralidade), "[...] de um desenvolvimento total, completo, multilateral, em todos os sentidos, das faculdades e das forças produtivas, das necessidades e da capacidade da sua satisfação [...]" (MANACORDA, 2010, p. 94).

Diante da proposta de Educação Profissional, faz-se necessário um currículo que preze por uma educação voltada para integralidade do ensino, que abarque os sentidos, articulando conhecimentos gerais e específicos e tendo o trabalho como princípio educativo.

Neste estudo, o destaque é no currículo do curso de Licenciatura em Química, construído em 2008, concomitante com a implantação do projeto do Campus do IFG (2008). Nessa época, a justificativa se baseou no fato da região de Uruaçu, que compreende outros nove municípios, possuir apenas um profissional com formação em Química para atender 14 escolas públicas de ensino médio, pois, conforme o IFG (2008, p. 9), "no ano de 2007 haviam sido matriculados nestes municípios um total de 5.502 alunos, além dos 1.268 alunos participando do programa de educação de jovens e adultos". Desse modo, a demanda era crescente, o número de alunos aumentava e necessitava de docentes com a formação específica em Química para atendê-los. Portanto, a partir do projeto de implantação (2008), constatou-se que essa formação não era oferecida na região, por ocorrer apenas nas cidades de Goiânia, Anápolis, Formosa, Itumbiara, Jataí, 
Inhumas e Rio Verde. Sendo assim, o curso foi implantado para suprir a demanda educacional, bem como a necessidade de profissionais devido ao crescimento e desenvolvimento econômico da região.

Conforme o documento do IFG, (2008, p. 10) o curso de Licenciatura em Química visa a "atender às necessidades do norte do Estado de Goiás quanto à formação de profissionais para exercer funções no magistério, no ensino fundamental e médio, bem como cursos profissionalizantes e indústria", sendo assim, o projeto do curso tinha como objetivo a

formação integral de professores qualificados para atuarem na Educação Básica com uma visão abrangente do seu papel social e com habilidades diversas para desempenhar seu trabalho de educador e esta formação deve incluir as disciplinas didáticopedagógicos e prática de ensino. A atuação do profissional se dará no Ensino Médio e nas séries finais do Ensino Fundamental (IFG, 2008, p. 13).

Em relação à "profissão professor", Tardif (2002) diz que ela se constrói fundamenta em quatro pilares: os saberes da formação profissional, os disciplinares, os curriculares e os experienciais que são construídos no decorrer de seu cotidiano. No plano de curso (2008), existe a confirmação de construção desses pilares conforme apresentado no Quadro 1, sobre os núcleos curriculares.

Quadro 1: Núcleos curriculares do curso de Licenciatura em Química

\begin{tabular}{|c|c|c|c|}
\hline \multicolumn{4}{|c|}{ NÚCLEOS CURRICULARES } \\
\hline $\begin{array}{l}\text { Disciplinas de } \\
\text { formação geral }\end{array}$ & $\begin{array}{c}\text { Disciplinas pedagógicas } \\
\text { específicas }\end{array}$ & $\begin{array}{c}\text { Disciplinas de formação } \\
\text { específica }\end{array}$ & $\begin{array}{l}\text { Prática e Estágio } \\
\text { supervisionado }\end{array}$ \\
\hline $\begin{array}{lr}\text { Constituído } & \text { por } \\
\text { disciplinas } & \text { que } \\
\text { visam à formação } \\
\text { humanística }\end{array}$ & $\begin{array}{l}\text { Organiza-se em disciplinas } \\
\text { comuns às licenciaturas e } \\
\text { em disciplinas específicas } \\
\text { da licenciatura em Química, } \\
\text { aprofundando-se em temas } \\
\text { importantes da educação e } \\
\text { do ensino e enfocando os } \\
\text { seguintes aspectos: visão do } \\
\text { papel da escola e do } \\
\text { educador; processo ensino- } \\
\text { aprendizagem } \\
\text { metodologia de ensino de } \\
\text { Química. }\end{array}$ & $\begin{array}{l}\text { Conhecimentos fundamentais } \\
\text { da Química, enfocando os } \\
\text { seguintes aspectos: } \\
\text { transformações químicas; } \\
\text { variáveis termodinâmicas e } \\
\text { cinéticas; estrutura e } \\
\text { propriedades da matéria; } \\
\text { análise química e físico- } \\
\text { química, manuseio e descarte } \\
\text { de produtos e resíduos } \\
\text { laboratoriais, visando à } \\
\text { segurança do trabalho e } \\
\text { conservação do meio } \\
\text { ambiente. }\end{array}$ & $\begin{array}{lr}\text { Serão } & \\
\text { responsáveis } & \text { pela } \\
\text { integração, ao } \\
\text { longo do } \\
\text { Curso, } \\
\text { conteúdos } \\
\text { formação } \\
\text { humanística, } \\
\text { pedagógica } \\
\text { específica, nas } \\
\text { dimensões } \\
\text { técnica, política e } \\
\text { ética. }\end{array}$ \\
\hline
\end{tabular}

Fonte: MEC (2018, p. 19-20).

Desse modo, ao analisar o Quadro 1, percebe-se que o currículo do curso possui, de maneira organizada e articulada, disciplinas que, no decorrer de sua formação, o aluno poderá desenvolver habilidades e competências necessárias para futuro exercício profissional. E ao final do curso, o futuro educador habilitado como Licenciado em Química concluirá uma carga horária total de 3.145 horas em 4 anos (IFG, 2008). 
O Núcleo Curricular, ao se referir ao item da "prática curricular e estágio supervisionado", define o estágio supervisionado como responsável pela integração dos conteúdos ao longo do curso, o que significa dizer que a prática como um:

Componente curricular, integra o ensino e, em decorrência do caráter reflexivo do qual deve se revestir, ocupa no projeto formativo uma dimensão análoga à dos demais componentes. Tem um papel fundamental na formação da identidade do professor como educador, articulando-se às disciplinas pedagógicas e específicas, às Atividades Acadêmico-Científico-Culturais e ao Estágio Supervisionado. Esta correlação teoria e prática é essencial para a formação do futuro professor no sentido de fomentar uma profissionalidade que tem como exigência um fecundo movimento entre saber e fazer na construção de significados para a gestão, a administração e a resolução de situações-problema próprias do ambiente educacional (IFG, 2008, p. 20).

Por isso, a relação teoria e prática nos cursos de formação inicial tem um papel muito importante na construção dos conhecimentos, atitudes e convicções dos futuros professores, por aquela ser necessária à identificação com a profissão.

O estágio, conforme Pimenta (1995), é uma atividade instrumentalizadora da práxis (atividade teórica e prática) educacional, da transformação da realidade existente. Por sua vez, para Libâneo (2015), é no estágio discente que a identidade docente se consolida uma vez que ela pode se desenvolver no âmbito do trabalho.

No caso da matriz curricular do curso de Licenciatura em Química, as disciplinas de prática e estágio supervisionado possuem carga horária conforme mostra o Quadro 2 de forma sintética.

Quadro 2: Disciplinas de atividades prática no curso - Matriz 2008

\begin{tabular}{|clc|}
\hline \multicolumn{2}{c|}{ Componentes curriculares } \\
\hline \multirow{2}{*}{ Período } & \multicolumn{1}{c|}{ Disciplina } & Carga Horária \\
\hline 5 & Didática & 54 \\
\hline 5 & Estágio Curricular Supervisionado - Etapa I & 80 \\
\hline 6 & Estágio Curricular Supervisionado - Etapa II & 80 \\
\hline 7 & Oficina de Ensino de Ouímica & 54 \\
\hline 7 & Estágio Curricular Supervisionado - Etapa III & 100 \\
\hline 8 & Estágio Curricular Supervisionado - Etapa IV & 100 \\
\hline \multicolumn{2}{c}{ Total } & $\mathbf{4 6 8}$ horas \\
\hline
\end{tabular}

Fonte: Adaptado IFG (2008)

No Quadro 2, as disciplinas de práticas e o estágio supervisionado somam 468 horas, sendo que, para atividades de estágio em campo, são apenas 360 horas, e o restante de 108 horas para aulas de didática e oficina de ensino de química, o que pode ser considerado como uma carga horária pequena diante da importância dessas 
disciplinas como, por exemplo, a didática e o estágio para a formação integral do aluno. Para Candau (2013), na formação de professores, a didática mostra o estreitamento do caminho ainda não percorrido, sendo por meio dela que se terá o elo tradutor de posicionamentos teóricos em práticas educacionais essenciais para o tal esperado professor reflexivo e mediador de reflexões.

Assim, na formação docente, a partir de Libâneo (2015), Pimenta (1995) e Candau (2013), a didática e o estágio supervisionado, bem como os saberes necessários para formação da docência, devem ser entendidos não como meros mecanismos de preparação sob o ponto de vista do "saber fazer", mas sim elementos que unem teoria e prática, entre o "que fazer" e o "como fazer" para ação e reflexão.

Entende-se, portanto, que o estágio supervisionado na formação de professores é de suma importância, pois, conforme afirma Freire (1991, p. 58), "ninguém nasce educador ou marcado para ser educador. A gente se faz educador, a gente se forma como educador, permanentemente, na prática e na reflexão sobre a prática". Nesse sentido, o currículo tem na didática um elo instrumentalizador entre teoria e prática.

Portanto, o estágio supervisionado é fundamental na efetivação desse elo e na construção da profissão e dos saberes docentes, pertencentes aos pilares da constituição do professor e de sua identidade como educador, o que será discutido na próxima seção: os saberes e a identidade docente.

\section{SABERES DOCENTES}

Ao retratar sobre os saberes docentes, Pimenta e Anastasiou (2010) evidenciaram que esses saberes se constituem e estruturam o todo da profissão professor. Isso quer dizer que, para ser docente, é preciso uma formação específica que considere o contexto da profissão de professor em sua complexidade. A partir dessas características é possível que se saiba quais foram os professores que mais contribuíram para a aprendizagem de seus alunos, em especial, para sua formação humanística e como os conhecimentos adquiridos ao longo desse processo de ensino, em que o protagonista foi o professor na formação inicial, farão parte de sua própria prática docente.

Não só isso, segundo Pimenta (2012), os alunos aprendem sobre o que é ser professor por meio da experiência socialmente acumulada ao longo dos anos, através das mudanças históricas da profissão, pelo exercício profissional em diversas instituições de ensino e através das políticas públicas de educação desenvolvidas no país. Além disso, as experiências de prática docente desses alunos em instituições precárias não oferecem as mínimas condições de ensino e, por fim, os estereótipos que partem da sociedade se relacionam negativamente à imagem do professor, desvalorizando a profissão.

Segundo Pimenta (2012), ao ingressar no curso de formação inicial, os futuros professores já possuem conhecimentos prévios sobre os saberes necessários para a prática docente. Esses conhecimentos são resultados da junção de diversas características de professores que, de uma maneira ou outra, deixaram um legado sobre o que é ser um bom ou mau professor. Essa mesma autora esclarece que o saber docente está intimamente ligado à prática como imitação de modelos. Ou seja, grande parte dos alunos aprende a partir da observação e imitação de seus professores, mas também desenvolvem seu próprio modo de ser pois, "nesse processo escolhem, separam aquilo que consideram adequado, acrescentam novos modos, adaptando-se aos contextos nos 
quais se encontram" no exercício da profissão docente. (PIMENTA, 2002, p. 7).

Retomando os quatro pilares que constroem os saberes da profissão do professor, conforme Tardif (2010), tem-se inicialmente os saberes profissionais, que são aqueles apropriados no decorrer da vida e da história do professor, adquiridos ao longo de sua formação inicial e continuada e que se fundamentam nas ciências da educação, portanto, constituem-se de um "conjunto de saberes transmitidos pelas instituições de formação de professores" (p. 36). Em relação aos saberes disciplinares, estes correspondem aos diversos campos do conhecimento, aos saberes de que dispõem a sociedade e que estão integrados às universidades sob a forma de disciplina.

Sobre isso, Tardif (2010, p. 38) diz que "os saberes disciplinares são integrados igualmente à prática do professor como os saberes profissionais e emergem da tradição cultural dos grupos sociais produtores de saberes sendo transmitidos nos diversos espaços educativos". Além disso, Tardif (2010) caracterizou os saberes docentes, o que comumente são chamados de discursos, objetivos, conteúdos e métodos que orientam o processo de ensino, pois são a partir destes saberes que as instituições escolares categorizam e apresentam os saberes sociais por elas definidos e selecionados como modelo da cultura que se diz erudita. E por último, Tardif (2010) chama de saberes experienciais aqueles desenvolvidos no trabalho cotidiano do professor. Esses saberes são incorporados à experiência individual e coletiva sob a forma de habitus, ou seja, o estilo próprio de ensinar, macetes da profissão e outras ações práticas que se incorporam aos saberes do professor enquanto parte identitária deste.

Nessa perspectiva, Tardif (2010) acrescenta que o "saber dos professores é o saber deles e está relacionado com a pessoa e a identidade deles, com sua experiência de vida e com sua história profissional, com suas relações com seus alunos em sala de aula e com os outros autores da escola" (TARDIF, 2010, p. 11). Completa, assim, a reflexão sobre os saberes docentes em que tanto Pimenta $(2002,2012)$ quanto Pimenta e Anastasiou (2010) e Tardif $(2000,2010)$ ponderaram sobre os saberes enquanto parte da identidade do ser professor.

Para Pimenta (2012), a identidade e perfil dos professores são construídos a partir da significação social da profissão, ou seja, os saberes docentes estão intrinsecamente associados à construção da identidade dos professores, enquanto prática e experiência educativas. Para esta autora, a identidade profissional do professor se constrói a partir da significação social da profissão, ou seja, do confronto entre as diversas práticas incorporadas à profissão docente, sendo ela resultado das significações sociais da profissão. Isso quer dizer que a identidade do professor é construída também pela incorporação de inovações que efetivam a prática de ensino e da análise sistemática das práticas à luz das teorias existentes, pois são elas que argumentam a favor de uma prática docente bem-sucedida.

Outro estudioso que também esclarece essa discussão é Nóvoa (1995). Para ele, a construção da identidade do professor é um processo de constituição do sujeito historicamente situado na sociedade que está em constante processo de mudança. Nesse sentido, a construção da identidade profissional docente se configura como um processo flexível e dinâmico e que deve levar em consideração as transformações sociais, políticas e culturais. Com isso, um processo importante na construção identitária do professor, 
JESUS, G. B. de; SILVA, Y. F. de Oe

segundo Nóvoa (1995), refere-se ao desenvolvimento profissional, ou seja, aos saberes acumulados a partir da teoria e da prática adquiridas ao longo de sua atuação. Partindo dessa perspectiva:

É preciso considerar que a formação de um professor, e consequentemente seu desenvolvimento profissional, resulta de um processo de construção de múltiplas identidades que repercutem direta e significativamente no fazer docente. Compreender-se como pessoa na profissionalidade contribui para a produção de sentido no trabalho docente (NÓVOA, 1995, p. 36).

Outrossim, a construção identitária do professor está relacionada ao seu perfil, exigindo competências e habilidades que, de acordo com Guedes e Sanchez (2017), atribuem uma complexidade na descrição de um perfil que possa caracterizar os professores da educação profissional e tecnológica.

No caso específico dos IFs, a realidade é mais complexa pelo fato de um professor transitar por vários níveis, formas e modalidades de ensino simultaneamente e por grande parte de seu quadro docente ser formado por engenheiros, bacharéis e tecnólogos, sem formação específica ou conhecimentos pedagógicos sistematizados, o que pode influenciar na sua prática pedagógica, pois exerce a profissão com públicos de diferentes faixas etárias. Sendo assim, a formação inicial do professor da educação profissional e tecnológica, além de contemplar os conhecimentos que lhe permitam uma prática pedagógica baseada em sua experiência cotidiana com os alunos, deve atuar como mediador do conhecimento e possibilitar uma formação integral do aluno.

\section{RESULTADOS E DISCUSSÕES}

A seguir, apresenta-se os resultados encontrados a partir da análise das entrevistas com os 5 participantes do estudo, ou seja, $40 \%$ do total geral de 12 alunos que estavam realizando o estágio supervisionado no segundo semestre de 2018 e finalizando o curso de Licenciatura em Química do IF Goiás, Campus Uruaçu. Os alunos foram nomeados e numerados da seguinte forma: $A Q 1, A Q 2, A Q 3, A Q 4, A Q 5$.

A primeira questão discorreu sobre a percepção dos alunos em relação à articulação e integração teoria e prática durante a formação no curso de licenciatura. Ao longo das entrevistas, notou-se uma total insatisfação dos alunos no que se refere à articulação entre teoria e prática no curso e também na sua formação crítica. As respostas foram na mesma direção em que se faz necessário maior articulação, aumento de carga horária para atividades práticas e de estágio supervisionado.

Alguns alunos (40\%) revelaram preocupação com o estágio, pois consideram a carga horária insuficiente, como observamos no Quadro 2, para colocar em prática todos os conhecimentos adquiridos em sala de aula, além da "falta de articulação entre as empresas e o IF no oferecimento de vagas de estágio no município" (AQ1). Além dessa falta de articulação, os entrevistados (40\%) citaram o número insuficiente de visitas técnicas, a falta de incentivo e orientações para pesquisas de iniciação científica e de atividades de extensão.

Conforme visto na seção anterior, a formação inicial deve considerar o contexto da profissão de professor em sua complexidade e o estágio é uma atividade 
instrumentalizadora da práxis (PIMENTA, 1995), o momento de articular teoria e prática e consolidar a identidade docente a ser desenvolvida no âmbito do trabalho (LIBÂNEO, 2015).

A segunda questão para os alunos participantes buscou conhecer como eles percebiam, no momento do estágio, a preparação para exercer a docência no mundo do trabalho. Todos os alunos entrevistados (100\%) sinalizaram que a formação para o trabalho precisa tanto da preparação técnica quanto de uma maior articulação entre a instituição e os arranjos produtivos locais e, com isso, haver a integração entre a teoria e a prática para uma melhor formação profissional.

A partir disso, a terceira questão se referiu às assertivas e fragilidades/entraves do currículo na formação dos alunos e futuros educadores. Por se tratar de um curso de licenciatura, a maioria dos alunos (80\%) respondeu que a preparação para o mundo do trabalho ainda possui aspectos a serem melhorados e citou, como exemplo, o estudo da disciplina de Didática, que possui, segundo o relato de um dos alunos participantes, uma carga horária de apenas 54 horas/aula. Essa carga horária deveria ser ampliada e "o estudo da didática para iniciar as atividades de estágio deveriam integrar todo o curso e iniciar no primeiro período, para que nós pudéssemos já ir habituando com a profissão" (AQ1). A disciplina que AQ1 fez referência chama-se Didática e foi ministrada no $5^{\circ}$ período, apresentada no Quadro 2.

Os entrevistados (100\%) atribuíram à falta de experiência e ao número alto de Licenciados em Química na região como principais entraves para sua inserção no mundo do trabalho. Somado a isso, os alunos esclareceram que os principais requisitos exigidos para sua contratação pelas empresas são o tempo de experiência e outros conhecimentos e habilidades, como boa comunicação e facilidade para trabalho em grupo.

A partir disso, foi evidenciada a preocupação com profissionais sem qualificação específica atuando, principalmente, nas escolas, e que "há um grande número de professores de Química (muitas vezes sem formação superior) contratados por 'indicação', não havendo preocupação da direção com a formação específica na área" (AQ4).

Voltando ao que o aluno (AQ1) trouxe em sua fala sobre a didática, não se pode perder de vista que, em termos gerais, a disciplina de Didática, que se preocupa com o estudo dos processos de aprendizagem na sua totalidade, tornou-se um dos principais indicadores dos professores na investigação dos fundamentos educacionais, organização escolar, teorias do conhecimento, métodos, conteúdos e organização da aula. Esses fundamentos embasam a relação ensino-aprendizagem e promovem a práxis educativa, até porque a didática:

Vem contribuir significativamente na fundamentação da prática educativa, de forma que os profissionais da educação possam ter um pleno domínio das bases teóricas científicas e tecnológicas, e sua articulação com as exigências concretas do ensino. Desta forma os profissionais da educação poderão estar revendo, analisando e aprimorando sua prática educativa (LIBÂNEO, 1994, p. 35).

A construção de uma nova didática, mais presente no cotidiano do aluno, é um 
grande desafio que deve estar presente na prática de ensino do educador, independentemente da modalidade de ensino. Dessa forma, é salutar a preocupação dos alunos entrevistados do curso de Licenciatura em Química em relação à disciplina que constitui a base para sua profissionalização, ou seja, a Didática.

Com a entrevista em andamento, uma última pergunta foi feita aos alunos sobre o entendimento deles da formação omnilateral, que é um dos objetivos da educação profissional. Acerca desse questionamento, apenas um entrevistado (AQ2) demonstrou compreender o seu significado ao responder que a omnilateralidade corresponde à formação "como um todo" do estudante. Penando nisso, há falhas no curso investigado em relação a este tipo de formação, principalmente pela falta de grupos de estudo e motivação que pudessem agregar mais conhecimentos aos alunos. Os outros alunos $(80 \%)$ não souberam responder e afirmaram não compreender o significado da palavra.

Para Frigotto (2012) e Manacorda (2007), uma formação omnilateral preconiza a integração de todas as dimensões do sujeito: trabalho, lazer, ciência e cultura, sendo capaz de proporcionar a ele compreensão do processo histórico de produção científica, tecnológica e cultural, configura-se, portanto, como educação emancipatória. Sobre isso, Marx (2004) também contribuiu ao esclarecer que a atividade prática, além da possibilidade de adquirir experiência, possibilita a aplicação e criação do saber teórico, por conseguinte, indispensável à formação omnilateral do indivíduo. Diante disso, essa sinalização deve ser repensada pela instituição visto que a definição do termo não está clara para os alunos, ainda que tenham indícios do entendimento de que a proposta do IF é de formação integral, de concretizar um ensino com senso crítico e desenvolver a preparação para o mundo do trabalho.

Após dez anos com a mesma matriz curricular, o projeto do curso passou por uma nova reestruturação. Para implantação a partir de 2019/1, as adequações podem ter ocorrido devido às mudanças econômicas do país e da região, pois, inicialmente, a demanda para essa formação era muito elevada. As mudanças mostradas no Quadro 3 revelam uma breve comparação da evolução curricular por trazer uma síntese da matriz aprovada no final do ano de 2018.

Quadro 3: Disciplinas de atividades prática no curso - Matriz 2019

\begin{tabular}{|c|c|c|}
\hline \multicolumn{2}{|c|}{ Componentes curriculares } \\
\hline Período & Disciplina & Carga Horária \\
\hline 1 & Didática em Laboratório de Ensino em Química & 54 \\
\hline 2 & Prática de Química Geral & 54 \\
\hline 3 & Prática de Química Inorgânica Experimental & 54 \\
\hline 4 & Prática Como Componente Curricular I & 54 \\
\hline 5 & Estágio Curricular Supervisionado I & 81 \\
\hline 5 & Didática & 54 \\
\hline 6 & Oficina de Ensino de Química & 54 \\
\hline 6 & Prática Como Componente Curricular II & 54 \\
\hline 6 & Estágio Curricular Supervisionado II & 81 \\
\hline 7 & Prática de Físico-química Experimental & 54 \\
\hline 7 & Estágio Curricular Supervisionado III & 108 \\
\hline 8 & Prática Como Componente Curricular III & 54 \\
\hline 8 & Estágio Curricular Supervisionado IV & 135 \\
\hline \multicolumn{2}{|}{ Total } & $\mathbf{8 9 1}$ horas \\
\hline
\end{tabular}


É perceptível o aumento significativo da carga horária tanto para estágio supervisionado quanto para as práticas de ensino e aulas de didática. Sobre isso, retomase a contribuição de Candau (2013) ao afirmar que é a didática que constrói o elo, a relação teoria e prática, pois ela não é somente um instrumento, mas também um elemento fundamental para a relação entre o conhecimento teórico-científico sendo necessária ao professor enquanto ainda acadêmico, bem como em sua prática como docente.

Assim, com a nova proposta pedagógica do curso, o IF Goiás está caminhando para superar alguns dos entraves apresentados pelos alunos entrevistados, a relação teoria e prática está em vias de ser, de fato, concretizada durante a formação do aluno, pois está contemplada na matriz curricular que será desenvolvida a partir do ano de 2019. As disciplinas de atividades práticas dessa proposta estão presentes desde o $1^{\circ}$ período até o último com um número de carga horária superior ao que era praticado na matriz anterior (2008-2018), na qual constavam 468 horas. Agora, essa carga horária passa para 891 horas segundo os Quadros 2 e 3, visando à formação integral do aluno, atender a sua expectativa, bem como a perspectiva de articulação entre teoria e prática na formação inicial do professor da educação profissional.

\section{CONSIDERAÇÕES FINAIS}

A discussão teórica teve como escopo referendar as percepções dos alunos do último período em momento de estágio supervisionado sobre a relação teoria e prática e sua preparação para exercer a docência no mundo do trabalho. Ao interpretar e analisar a percepção dos alunos do curso de Licenciatura em Química constatou-se uma insatisfação dos entrevistados em relação à articulação entre teoria e prática no que tange ao estágio supervisionado do referido curso. No momento de finalização de sua formação inicial e prestes a ingressar no mundo do trabalho, os alunos entrevistados ainda não se sentem totalmente preparados para o exercício da docência, provavelmente por evidenciarem uma lacuna nas atividades de estágio que pode ser traduzida na dificuldade em perceber a efetiva relação teoria e prática.

Sendo assim, juntamente aos alunos, corroboramos suas percepções sobre a necessidade de uma educação dialética, construída no arcabouço de um processo de ensino que aproxime a teoria da prática comumente exigidas para a profissionalização e aproximação do mundo do trabalho, recuperadas pela articulação do estágio com o saber efetivo adquirido em sala de aula, grupos de estudos, enfim, de um processo de ensino que possa realmente traduzir-se na integração entre a instituição de ensino e a escola campo, na formação integral do indivíduo.

É possível perceber que o IFG tem se preocupado com as mudanças significativas que interferem na proposta curricular de seu curso, pois na redefinição do currículo temse um avanço da matriz curricular em relação às práticas de ensino e didática que inferem na relação e aplicação de atividades que articulam teoria e prática, bem como, desde $1^{\circ}$ período, amplia-se também progressivamente a carga horária exigida de atividades de estágio supervisionado. Isso se deve às discussões que vêm se acirrando pela necessidade de que a formação no âmbito do IF Goiás deve partir do princípio de integração entre currículo geral e específico, o trabalho como princípio educativo e por meio de um ensino 
JESUS, G. B. de; SILVA, Y. F. de Oe

que seja interdisciplinar (MEC, 2018).

Enfim, a percepção dos alunos deve ser considerada para a continuidade das discussões e para a consolidação dos conhecimentos oferecidos no curso de Licenciatura em Química do IFG, Campus Uruaçu, reconhecendo que, para a efetividade da proposta de ensino desta instituição, faz-se necessário repensar e primar pela melhoria da articulação entre teoria e prática e maior integração com as escolas campo. Ao finalizar este estudo, fica a expectativa, ainda que haja muito desafios, de uma nova matriz que busque superar a falta ou pouca articulação e integração da teoria com a prática no curso de Licenciatura em Química do IF Goiás, Campus Uruaçu.

Artigo recebido em: 31/01/2019

Aprovado para publicação em: 15/04/2019

\section{PROFESSIONAL EDUCATION AND THE HIGHER COURSE OF AN IFG GOIÁS CAMPUS: PERCEPTION OF STUDENTS IN THE CONTEXT OF THE SUPERVISED INTERNSHIP}

ABSTRACT: This study seeks to uncover the students' perception of an IFG campus about their training and insertion in the world of work. The question of interest is: what is their perception about their initial formation, assertive and fragile to access the world of work, to the exercise of teaching and yet, their perception about the articulation and integration of theory and practice during their course? The theoretical framework adopted stands out among others Nóvoa (1995), Pimenta (1995), Tardif (2010) and Candau (2013). This research is characterized as a work of a qualitative nature with the use of an interview script for undergraduate students in Chemistry. When interpreting and analyzing the students' perception of the course, it was verified a dissatisfaction among the interviewees regarding the articulation between theory and practice regarding the supervised internship. In contrast, it is possible to perceive that the IFG has been concerned with the significant changes that interfere in the curricular proposal of its course, for presenting a redefinition of its curriculum and the advance of the curricular matrix in relation to teaching and didactic practices.

KEYWORDS: Professional Education. Supervised and didactic internship. Integral training and curriculum. Theory and practice.

\section{EDUCACIÓN PROFESIONAL Y EL CURSO SUPERIOR DE UN CÁMPUS DEL IFG GOIÁS: PERCEPCIÓN DE LOS ALUMNOS EN EL CONTEXTO DE LA PASANTÍA SUPERVISADA}

RESUMEN: Este estudio busca desvelar la percepción de los alumnos de un campus del IFG sobre su formación e inserción en el mundo del trabajo. La cuestión de interés es: ¿cuál es su percepción sobre su formación inicial, asertivas y fragilidades para acceder al mundo del trabajo, para el ejercicio de la docencia y aún, su percepción sobre la articulación e integración de la teoría y práctica durante su curso? El referencial teórico adoptado destaca entre otros Nóvoa (1995), Pimenta (1995), Tardif (2010) y Candau (2013). Esta investigación se caracteriza como un trabajo de naturaleza cualitativa con uso de guión de entrevista para alumnos del curso de Licenciatura en Química. Al interpretar y analizar la percepción de los alumnos del curso se constató una insatisfacción de los 
entrevistados en relación a la articulación entre teoría y práctica en lo que se refiere a pasantía supervisada. En contrapartida es posible percibir que el IFG se ha preocupado por los cambios significativos que interfieren en la propuesta curricular de su curso, por presentar una redefinición de su currículo y el avance de la matriz curricular en relación a las prácticas de enseñanza y didáctica.

PALABRAS CLAVE: Educación Profesional. Pasantía supervisada y didáctica. Formación integral y currículo. Teoría y práctica.

NOTA

1) Este estudo integra a dissertação do Programa de Pós-Graduação Stricto Sensu Interdisciplinar em Educação, Linguagem e Tecnologias oferecido pela Universidade Estadual de Goiás (UEG).

\section{REFERÊNCIAS}

BRASIL, Ministério da Educação. Lei no 11.892 de 07 de outubro de 2008. Institui a Rede Federal de Educação Profissional, Científica e Tecnológica, cria os Institutos Federais de Educação, Ciência e Tecnologia, e dá outras providências. Diário Oficial da República Federativa do Brasil, Brasília, 2008. Disponível em: http://www.planalto.gov.br. Acesso em: 12/01/2019.

BRASIL. CNE/CEB. Atualização das Diretrizes Curriculares Nacionais para a Educação Profissional Técnica de Nível Médio. Brasília, CNE. CEB, 2011.

BRASIL. Ministério da Educação. Concepções e Diretrizes - Instituto Federal de Educação, Ciência e Tecnologia. Brasília, PDE/SETEC, 2008

CANDAU, V. M. (Org). Rumo uma Nova Didática. 23. ed. Petrópolis, RJ, Vozes,2013.

CIAVATTA, Maria. O trabalho docente e os caminhos do conhecimento: a historicidade da Educação Profissional. 1. ed. Rio de Janeiro, Lamparina, 2015.

FREIRE, Paulo. A educação na cidade. São Paulo, Cortez, 1991.

FRIGOTTO, G. A relação da educação profissional e tecnológica com a universalização da educação básica. Revista Educação e Sociedade, Campinas, v. 28, n. 100, 2012.

GUEDES, I. A. C.; SANCHES, L. B. A formação docente para a educação profissional técnica e sua influência na atuação dos professores do Instituto Federal do Amapá: campus Macapá: um estudo de caso. Revista Holos, Rio Grande do Norte, v.7, n.33, 2017. 
JESUS, G. B. de; SILVA, Y. F. de Oe

IFG - Instituto Federal de Educação, Ciência e Tecnologia de Goiás. Resolução n. 057, de 17 de novembro de 2014. Disponível em: http://www.ifg.edu.br/eventos-emandamento/61-ifg/pro-reitorias/ensino/7330-regulamento-estagio-2. Acesso em: 10 jan. 2019.

IFG - Instituto Federal de Educação, Ciência e Tecnologia de Goiás. Plano de Desenvolvimento Institucional: 2012 a 2016. IFG. Goiânia, 2013.

IFG - Instituto Federal de Educação, Ciência e Tecnologia de Goiás. Projeto Pedagógico do Curso de Licenciatura em Química. Uruaçu, Campus Uruaçu, 2018.

IFG - CEFET - Centro Federal de Educação Tecnológica de Goiás. Unidade de Uruaçu Goiás. Projeto de implantação do curso Licenciatura em Química - Uned Uruaçu. Uruaçu, Out/2008.

LIBÂNEO, J. C. Didática. São Paulo, Cortez, 1994.

LIBÂNEO, José Carlos. Organização e gestão da escola: teoria e prática. 6. ed. rev. e aum. São Paulo, Heccus, 2015.

MANACORDA, M. A. L. Marx e a pedagogia moderna. Campinas, Alínea, 2010.

MANFREDI, Sílvia Maria. Educação profissional no Brasil. São Paulo, Cortez, 2002.

MARX, K. Processo de trabalho e processo de valorização. São Paulo, Expressão Popular, 2004.

NÓVOA, A. (Org). Os professores e sua formação. Lisboa, Dom Quixote, 1995.

PACHECO, E. Os institutos federais: uma revolução na educação profissional e tecnológica. 2019. Disponível em: http://portal.mec.gov.br/setec/arquivos/pdf/insti evolucao.pdf. Acesso em: 10 jan. 2019.

PIMENTA, S. G. Formação de professores: identidade e saberes da docência. In: PIMENTA, S. G. (Org). Saberes pedagógicos e atividades docentes. São Paulo, Cortez, 2012.

PIMENTA, S. G. De professores, pesquisa e didática. Campinas, Papirus, 2002.

PIMENTA, S. G. O estágio na formação de professores: unidade entre teoria e prática? $2^{\mathrm{a}}$ ed. São Paulo, Cortez, 1995.

PIMENTA, S. G.; ANASTASIOU, L. G. C. Docência no ensino superior. 4. ed. São Paulo, Cortez, 2010.

TARDIF, M. Saberes docentes e formação profissional. 10 ed. Petrópolis, Vozes, 2010. 
TARDIF, M.; RAYMOUND, D. Saberes, tempo e aprendizagem do trabalho no magistério. Revista Educação e Sociedade, Campinas, Unicamp, v. 21, n. 73, dez., 2000.

Gilmara Barbosa de Jesus: Mestranda do Programa de Pós-Graduação em Educação, Linguagem e Tecnologias-PPGIELT da Universidade Estadual de Goiás-Campus Anápolis de Ciências Socioeconômicas e Humanas (CCSEH).

Orcid: http://orcid.org/0000-0003-0480-8528

E-mail: sbarbosadejesus@gmail.com

Yara Fonseca de Oliveira e Silva: Doutora em Políticas Públicas, Estratégias e Desenvolvimento (UFRJ/PPED/UEG, 2014) e Pós-doutora na Faculdade de Letras da Universidade do Porto-Portugal. Mestre em Educação pela Universidade Federal de Goiás (FE/UFG, 2005). Professora titular da Universidade Estadual de Goiás, Campus Aparecida de Goiânia e docente do Programa Interdisciplinar em Educação, Linguagem e Tecnologias (PPG-IELT) da UEG. Experiência na área de Educação e pesquisadora dos temas: educação superior, políticas públicas, políticas educacionais, formação de professores, economia da inovação e diversidade.

Orcid: https://orcid.org/0000-0001-5725-478X

E-mail: yarafonsecas09@gmail.com

Este periódico utiliza a licença Creative Commons Attribution 3.0, para periódicos de acesso aberto (Open Archives Iniciative - OAI). 